\title{
Automated detection of slum area change in Hyderabad, India using multitemporal satellite imagery \\ Oleksandr Kit, Matthias Lüdeke
}

\begin{abstract}
This paper presents an approach to automated identification of slum area change patterns in Hyderabad, India, using multi-year and multi-sensor very high resolution satellite imagery. It relies upon a lacunarity-based slum detection algorithm, combined with Canny- and LSD-based imagery pre-processing routines. This method outputs plausible and spatially explicit slum locations for the whole urban agglomeration of Hyderabad in years 2003 and 2010. The results indicate a considerable growth of area occupied by slums between these years and allow identification of trends in slum development in this urban agglomeration.
\end{abstract}

Keywords: slum identification, urban remote sensing, Hyderabad

\section{Introduction}

Despite all the multi-scale efforts, slums continue to shape considerable part of many large urban agglomerations in developing and newly industrialized countries as of 2013. It is generally accepted that highly crowded, underserviced and dilapidated informal settlements (UN, 2011) are currently home to approximately 828 million people (UN, 2012). Rapid urbanisation, social and demographical change and weakness of institutions have all contributed to the fact that the slum population of India remains being the highest in the world (UN, 2012). According to official figures, $22 \%$ of the total population of India's cities and, more specifically, 35\% of the population of the city of Hyderabad lives in slums (Census of India, 2001). The Government of India (Government of India, 2010) expects country's slum population to exceed 100 million by 2015 . 
The reliability of national sample surveys and other official statistics on slums in India has often been questioned in the literature (Satterthwaite, 2010; Agarwal, 2011; Risbud, 2010), while the cause of errors has been often attributed to the stealthy nature of slums and difficulties of data collection. Hyderabad is not an exception: a survey carried out by the Centre for Good Governance in 2008 stumbled upon a problem that 146 slums from the slum list provided by the Municipal Corporation of Hyderabad did not exist at the time of survey. Furthermore, 21 slums were replaced by multi-level apartments, shopping centres etc (Centre for Good Governance, 2008).

Discussing different methods of data acquisition for mapping of slums, Kohli et al., 2012 distinguishes between census-based, participatory and remote sensing-based approaches. Counting individual dwelling units in situ is undoubtedly the most reliable method of slum area estimation. Although very accurate, this method is extremely time- and effort-intensive. Satellite imagery of cities only reflects the spatial and spectral morphology of urban fabric and cannot replace traditional socio-economic data collection methods. Nevertheless, it has been proven that spatial characteristics of land cover elements such as rooftops, soil, and vegetation can serve as proxies for the identification of both slum-like areas and residential areas associated with higher socioeconomic status (Weeks et al., 2007). Remote sensing and advanced image processing methods have the potential to offer a worthy alternative to field data collection in certain situations. By virtue of its uniformity, satellite imagery is a useful tool to address the paucity of data on urban settlements in the global South and belongs to an active field of research on urbanisation patterns in developing and newly industrialised countries.

Successful examples of slum identification from very high resolution imagery include methods based on object-based image analysis (Hofmann et al., 2008), object segmentation and classification (Shekhar, 2012), morphological opening and closing (Rhinane et al., 2011). One of the last successful attempts to automatically identify slums in India has been made by Shekhar, 2012, where eCognition-supported object segmentation and classification has been used to identify slums in Pune. The author reaches identification accuracy of $87 \%$ as benchmarked against the slum survey using classification rules such as structure size and density, street pattern irregularity and vegetation distribution. Characteristic physical features and heterogeneity of urban morphology have been used by Taubenböck and Kraff (2013) to delineate a set of slum areas in Mumbai from a morphological point of view and to confirm their separability from formal settlements. 
The slums in a city do not evolve overnight. Establishing and disappearance of slums is a steady process that which may take anything from days (in case of slum removal actions) to decades. Many of the studies mentioned above have been successful in employing automated or semi-automated methods to identify slum extent from a single satellite scene, but surprisingly few studies so far addressed the multitemporal dimension of slum identification in the same city. This is on one hand explained by limited temporal availability of very high resolution satellite imagery obtainable at reasonable costs, and on the other hand - by imperfectness of automated slum identification methods.

Nevertheless, this field of research is not completely barren. QuickBird and GeoEye imagery has been successfully used by Veljanovski et al., 2012 to analyse settlement growth and changes in Kibera slum, Nairobi using object-based contextual classification methods between years 2006 and 2009. Jain, 2007, analysed slum evolution between 2001 and 2005 in Dehra Dun, India using manual visual interpretation techniques of Ikonos imagery. These studies were, however, either confined to parts of urban agglomerations or analysed relatively small cities.

This work continues and enhances previous studies in the field by Kit et al., 2012 and Kit et al., 2013. It is not limited to improvement of automated slum identification methods developed earlier, but goes a step further and attempts to capture the spatio-temporal dynamics of urban fabric change in Hyderabad by analysing slum-related land use change in the whole megacity area between the years 2003 and 2010.

\section{Study area}

Hyderabad is the capital of Andhra Pradesh state in central South India. It grew from about one million inhabitants in 1951 to about seven million in 2001. The urban agglomeration is expected to host 10 -million inhabitants by around 2020, whereas the scenarios for the wider urban area project population size of 13 million in 2021 and 18 million in 2031 (HMDA, 2011).

According to the GHMC commissioner as quoted by The Times of India, 2012, Greater Hyderabad hosts 1476 slums, 1179 of which are notified. 66\% of the city's total slum population of 1.7 million live in the core area (erstwhile $\mathrm{MCH}$ ), while the rest lives in the periphery of the city. The official datasets available through different local government agencies (Figure 1) are very fragmented and are neither consistent between each other, nor plausible when compared to the satellite imagery. While the total number of slums reported by the Hyderabad Metropolitan Development Authority (HMDA) does roughly match the one reported by the Greater Hyderabad Municipal Corporation 
(GHMC) (700 vs. 637), their spatial distribution is different, with only $25 \%$ of slums matching each other's location within $100 \mathrm{~m}$ buffer. Furthermore, no data is provided for the urban area outside of the $\mathrm{MCH}$ core.
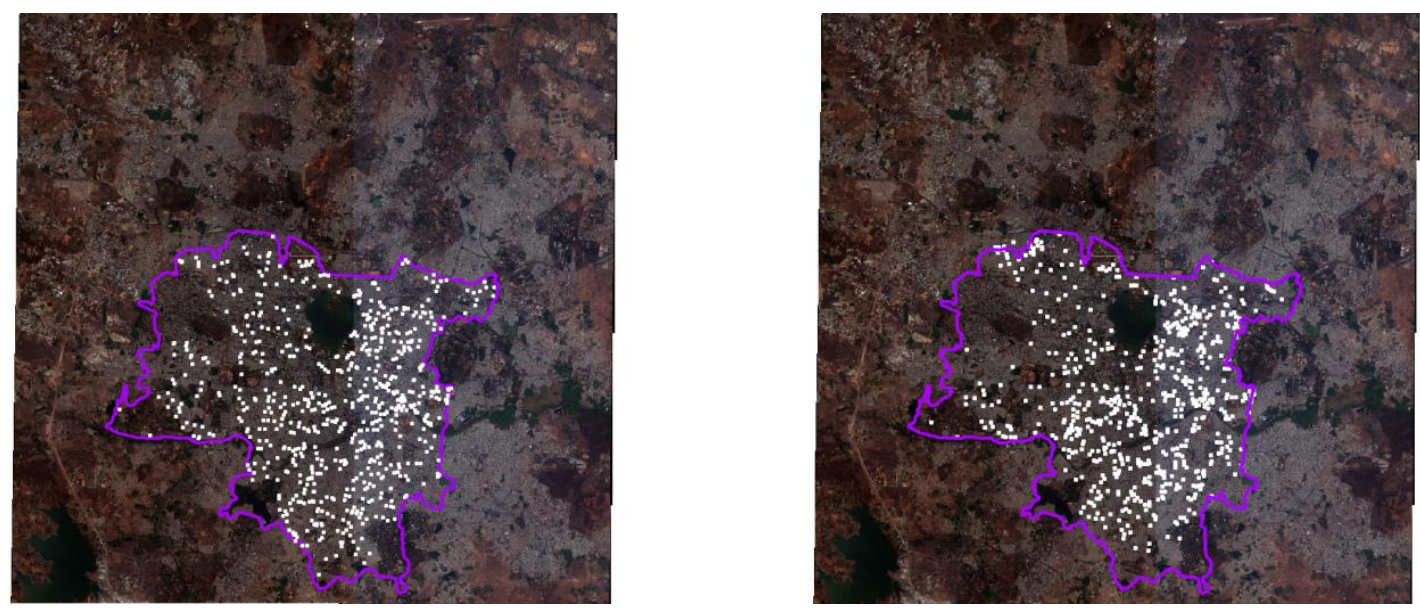

Figure 1. Official slum maps of Hyderabad according to HMDA (left) and GHMC (right)

The automated slum detection algorithm has been applied to the following imagery:

- QuickBird full swath (11 bit) cloudless mosaic, acquired on 27 May and 11 June 2003, and

- WorldView 2 full swath (11 bit) cloudless mosaic, acquired on 3 and 14 February 2010

The imagery used in this study was delivered by the data provider as a gridded dataset which was radiometrically calibrated, pan-sharpened, corrected for sensor- and platform-induced distortions and mapped to a UTM projection zone $44 \mathrm{~N}$. The data covers $400 \mathrm{~km}^{2}$ of urban territory within a rectangular bounding box of $78^{\circ} 22^{\prime \prime}-34^{\prime \prime}$ east longitude and $17^{\circ} 18^{\prime \prime}-30^{\prime \prime}$ north latitude; this corresponds to the image size of 38,144 by 68,287 pixels.

\section{Methodology}

The starting point of our analysis is the relation between the lacunarity value of a $60 \times 60 \mathrm{~m} \mathrm{(100x}$ 100 pixels) image of an urban subarea and the probability that this subarea is morphologically similar to a slum. Lacunarity is a specific measure of spatial heterogeneity that identifies the 
granularity of the visible urban structure. It is sensitive to quasi-regularly repeated small objects and an elaboration of structural measures like the fractal dimension (Amorim et al., 2009). Lacunarity has been successfully used for slum identification in Hyderabad by Kit et al., 2012.

A very sensitive part of the lacunarity-based slum detection algorithm is the preparation of binary images describing the surface. In an ideal case, all housing units within a city would be marked as 1 , and everything between them - as 0 . This is, however, barely possible to achieve when performing automated satellite imagery analysis in a city like Hyderabad, where vectorised housing maps are not readily available and the housing structure in many neighbourhoods is highly informal. Where human eye can quickly comprehend a scene and identify artificial features such as individual buildings irrespective from dwelling unit size or roof material variability, a computer algorithm requires multiple preparatory steps. Therefore, it was important to design a binary data preparation routine which would be successful in converting true-colour satellite imagery of a city into binary raster of pseudo built-up areas (Owen and Wong, 2013).

Automated multitemporal urban satellite imagery analysis is sensitive to the position of the sun because of the difference in shadows across multiple images. Shadows are a particular problem for high resolution imagery, where a shadow from a typical one- to three-storey house in India can stretch across several pixels of the image and therefore considerably reduce the object identification and object comparison quality. Typical cloud-free urban satellite imagery is very often assembled from a mosaic of scenes, recorded during satellite revisit flights. Therefore, the position of the sun varies not only between multi-year imagery, but also within a one-year scene. Even though imagery providers typically include the exact time of imagery acquisition (and hence the height of the sun over horizon) for every piece of the mosaic, correction of shadow effects in high resolution images of urban areas is a very complex and error-prone task (Zhan et al., 2005). Therefore, we were looking for an urban fabric analysis algorithm which would be rather insensitive to the shadows and would mainly identify the edges of buildings.

Veljanovski et al., 2012 cites the discrepancy between informal area outer-homogeneity and innerheterogeneity due to the microstructure of urban agglomeration as one of the reasons why automated object delineation (and thus object-based analysis) in slum-like areas often produces poor results. Generation of binary maps which carry object/non-object signals and are suitable for temporal analysis therefore remains a problematic step of automated urban slum identification methods. Our earlier studies used principal component analysis (PCA) and Gaussian line detection 
algorithms to correctly identify slums on a 2003 image, but were less successful to produce consistent and ground truth-verified results with multitemporal satellite imagery obtained from two different platforms. To overcome this limitation and to perform fully automated detection of slum area change in Hyderabad, after a thorough comparison of several methods of binary raster generation we decided to use the combination of two advanced image analysis methods: canny edge detection and LSD straight line detection. We tested the Laplacian of Gaussian edge detector as well, but ruled it out after analysis of data provided by Figure 2 and Table 1.

\subsection{Laplace of Gaussian}

The Laplacian of the Gaussian is an edge-detection filter which highlights regions of rapid intensity change on an image that has been Gaussian-smoothed to reduce its sensitivity to noise. It is commonly used as a second-order edge detector in image processing (Gunn, 1999). The method was proposed by Marr and Hildreth, 1980, as a physiological model of the early human visual system. The filter has been successfully used to analyse satellite imagery of urban areas and perform feature extraction by Bong et al., 2009, and Ünsalan, 2009.

\subsection{Canny}

Canny detector is a powerful edge detector that generates single-pixel wide continuous lines along the significant edges within the image (Canny, 1986). It is widely regarded as the edge detection standard. This is a multistage algorithm which combines Gaussian noise reduction, non-maximum suppression and hysteresis thresholding of an image. It is adaptable to various environments and has been repeatedly used in object extraction and land use studies using high resolution urban satellite imagery (most recent applications include Peeters and Etzion, 2012, Awrangjeb et al., 2010, Grigillo et al., 2012).

\section{3. $L S D$ line detection}

LSD straight line detection algorithm is an automated image analysis tool which is aimed at identifying locally straight contours on images (von Gioi et al., 2012). It takes a grey-level image as input and returns a list of detected straight line segments. Its application to urban and periurban remote sensing included separation of formal and informal settlements in Algeria (Khelifa and Mimoun, 2012), extraction of buildings (Poulain et al., 2011) or landscape analysis (Bailly and Levevasseur, 2012).

Figure 2 presents a sample of the original satellite imagery and the binary datasets obtained using each of the data preparation methods described above. 


\section{3}

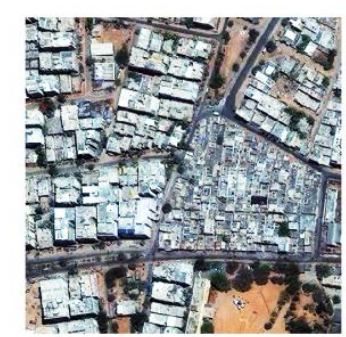

a)

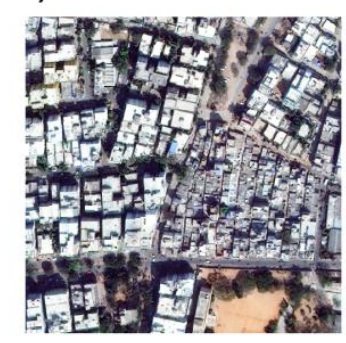

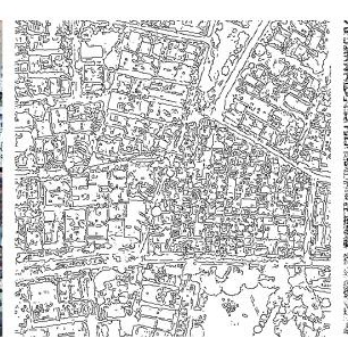

b)

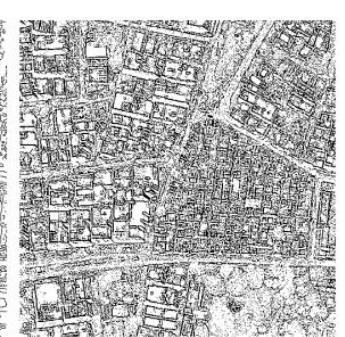

c)

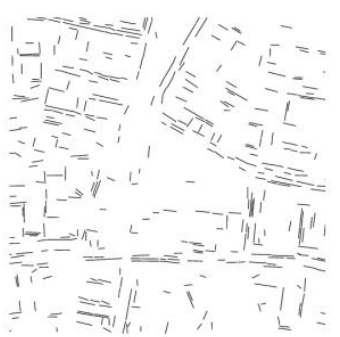

d)

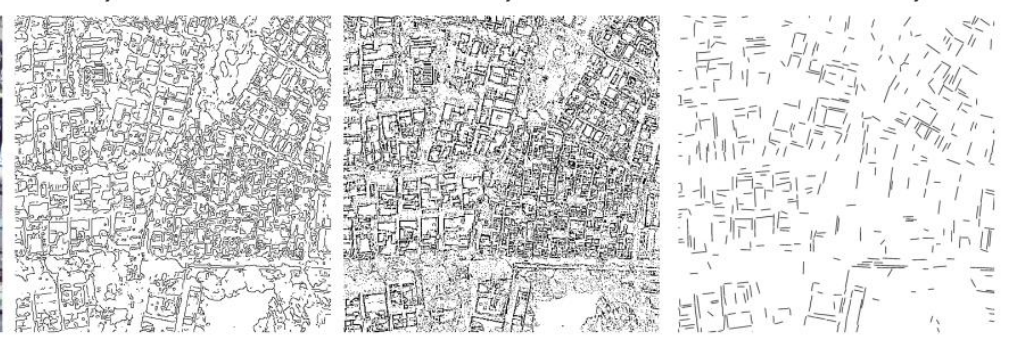

\section{0}

Figure 2. Comparison of original satellite imagery (a), Laplacian of Gaussian (b), Canny (c) and LSD (d) binarisation algorithms for 2003 and 2010 scenes.

The comparison of performance and comparability of binary image generation methods used an extract of the satellite image (Figure 2, Parvath Nagar area in the north-western part of the city) where the observed land use change between 2003 and 2010 has been utterly insignificant. The goal of this step was to identify a method which would produce the most similar binary maps for both time slices in question. To quantify similarity of images, we computed and compared lacunarity values for all binarisation methods and time slices. The results are presented by Table 1 :

Table 1. Lacunarity values for binary images representing area which did not change between 2003 and 2010

\begin{tabular}{|l|l|l|l|}
\hline & Laplace of Gaussian & Canny & LSD \\
\hline 2003 & 1.07 & 1.13 & 2.52 \\
\hline 2010 & 1.11 & 1.15 & 2.03 \\
\hline Difference: & 0.04 & 0.02 & 0.49 \\
\hline
\end{tabular}

This analysis allows us to conclude that Canny edge detection method produces the smallest difference in the lacunarity values between two time slices, meaning that the algorithm ensures the 
highest degree of morphological similarity between both binary images. Visual analysis of the images confirms this conclusion.

The final pre-processing algorithm combines the strengths of Canny edge detection and LSD line detection method. Canny edge detection is capable to correctly outline sharp edges within a satellite scene. In many cases these are roof-street or roof-roof boundaries. However, the algorithm identifies many other sharp boundaries within the city, such as these within park and agricultural zones, road elements, or, especially, exposed rock formations. In many cases the spectral signatures of such morphological areas are very similar to housing regions, making it very difficult to exclude them from the slum identification process. The distinctive signal which reasonably well distinguishes human habitations from exposed rocks is the rectangular shape of individual features within the area, as human settlements in India and especially these in slums tend to consist of straight-lined structures.

This was the reason behind decision to perform one more data processing step and to exclude areas which contained less than 2 LSD points per $100 \times 100$ pixels square. The 2 pixel threshold has been obtained empirically as such that reasonably well excludes rock formations and vegetation forms in Hyderabad without influencing human settlements.

Figure 3 summarises automated slum identification process in a flowchart.

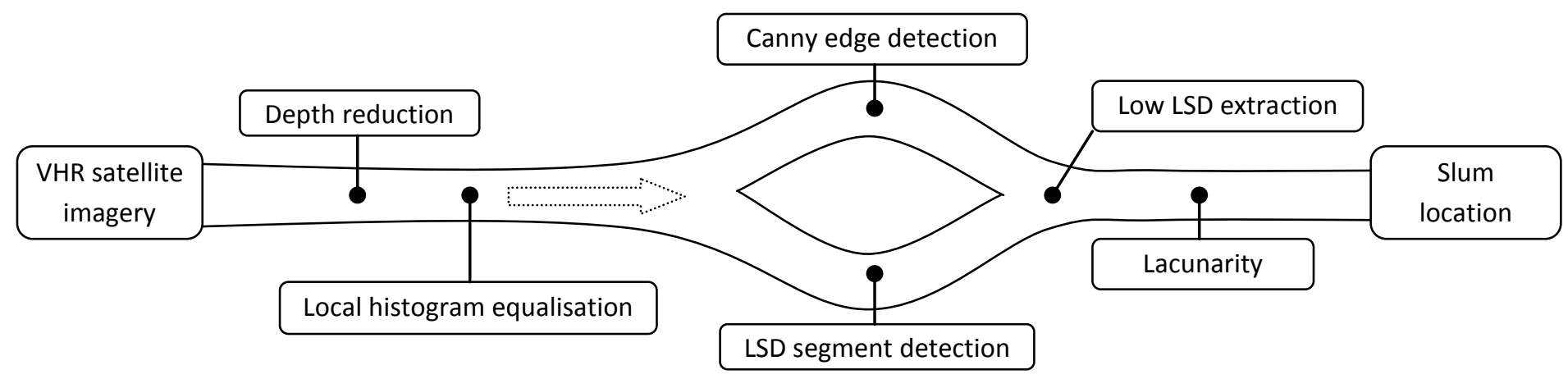

Figure 3. Slum identification algorithm flowchart

The authors used VIPS image processing system ${ }^{1}$ in conjunction with scikit-image ${ }^{2}$ and LSD $^{3}$ libraries and a custom developed lacunarity calculation routine in a mixed C++/Python programming

\footnotetext{
${ }^{1}$ http://www.vips.ecs.soton.ac.uk

${ }^{2}$ http://scikit-image.org/
} 
environment. This final algorithm performed equally well on 2003 and on 2010 imagery and did not require additional calibration or modification, neither between different components of the satellite mosaic nor between the time slices.

\section{Results}

The application of the slum identification method described above yields the results depicted by Figure 4, which compares identified slum locations in Hyderabad in 2003 to these in 2010.

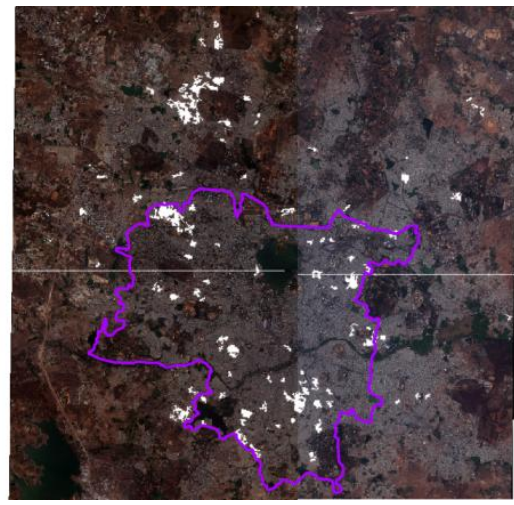

a) Detected slums 2003

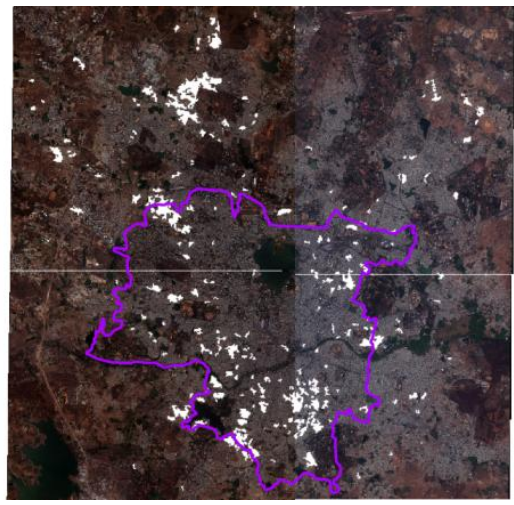

b) Detected slums 2010

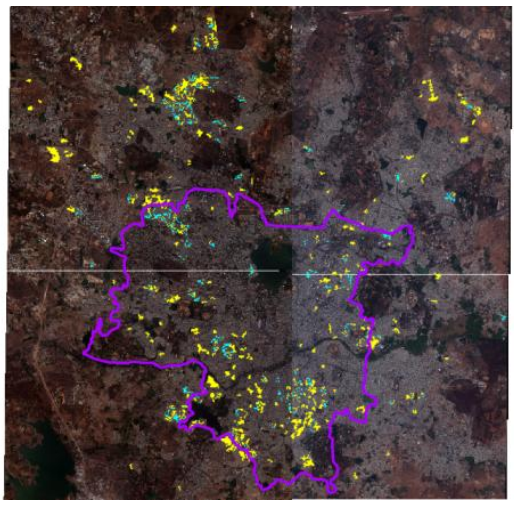

c) Difference map (yellow: new slums, blue - disappeared slums

Figure 4. Automatically identified slums of Hyderabad in 2003 and 2010.

The full resolution KML files containing data shown my Figure 4 are provided as a multimedia attachment to this article. The spatial distribution of slums in both scenes is relatively similar and is confined to the outer circle of the city and to the Old Town on the right bank of river Musi. The most substantial difference between these two time slices is an overall increase in existing slum size, as well as establishment of new slums in the south and in the north of the city. The results of automated slum identification indicate a 70\%- increase of the area covered by slums between 2003 and 2010, approximately from 11 to $19 \mathrm{~km}^{2}$. Very few informal settlements appeared on previously completely uninhabited land, the vast majority of slum areas evolved in the process of densification of more spacious settlements or as the result of growth of existing slums, conforming to a typical slum growth process described by Sliuzas et al., 2008.

The importance of combination of Canny and LSD algorithms for error reduction in slum identification process is demonstrated by Figure 5. It depicts a very heterogenous area which combines rock formations, vegetation, slum and non-slum land use types in the vicinity of the Muzaffar Ahmad Nagar slum in the Miyapur part of the city (Figure 5-a). The lower and the right part of the image are occupied by slums; the upper part - by exposed rock formations. Because of high

\footnotetext{
${ }^{3}$ https://github.com/theWorldCreator/LSD
} 
contrast to the surrounding terrain and high density of distinct features, these area produce similarly dense Canny line patterns (Figure 5-b) and therefore yield in similar lacunarity values (Figure 5-c). The only difference of a built-up area is the density of straight lines, and these are captured by the LSD algorithm only (Figure 5-d). The final lacunarity raster only contains cells on in the bottom and on the right of the subset, and these are the slum cells (Figure 5-e).

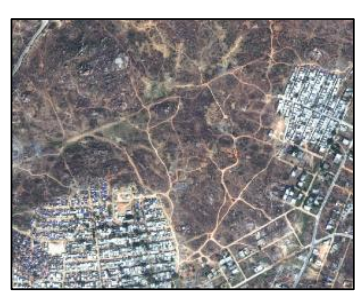

a) Original image

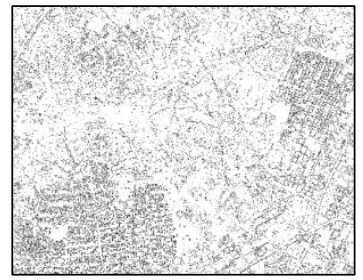

b) Canny edges

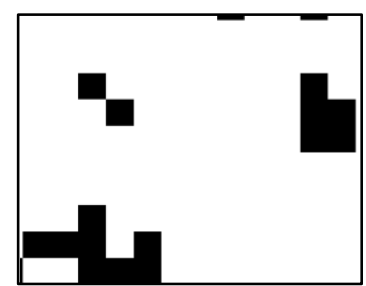

c) Thresholded lacunarity

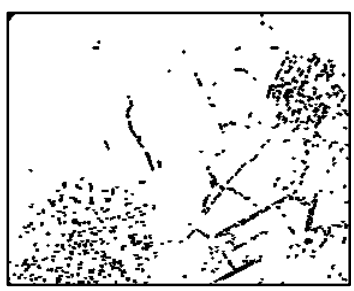

d) LSD segments

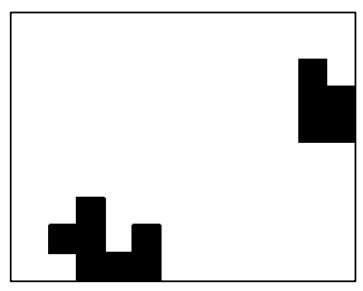

e) Final thresholded lacunarity

Figure 5. Example of combination of Canny and LSD algorithms for slum identification.

The ability of the algorithm to analyse different time scenes and to document slum establishment process using multitemporal imagery from different sensors is demonstrated by Figure 6, which reveals changes in slum coverage in the I.S.Sadan area of Hyderabad. The previously large open space area in the centre of the image (Figure 6-a) has been built up by two types of housing: modern high-rise residential blocks and a $\Pi$-shaped high density slum (Figure 6-b), which probably hosts construction labourers and servants. The shape and extent of the newly established slum have been correctly identified by the algorithm (Figure 6-c).
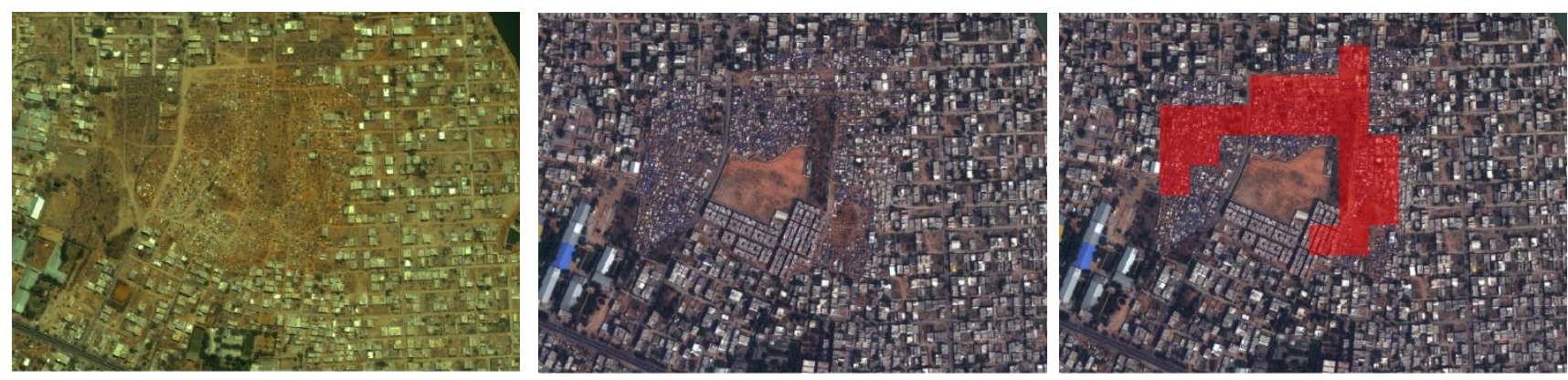
Figure 6. Establishment of a slum at I.S.Sadan area

To verify the performance of the algorithm and the quality of slum identification, a series of ground truthing visits has been conducted (Bostel, 2012). In total, 8 evenly distributed ground truthing sites with positive identification signal produced by the algorithm have been selected (Figure 7), 7 of which (87\%) confirmed presence of slums in that area. The results of ground truthing are summarised in the Table 2, the on-site area description followed the Indian building typology by Baud et al., 2010.

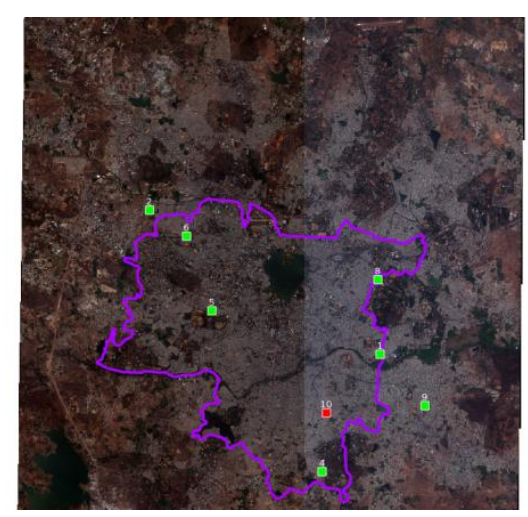

Figure 7. Ground truthing sites (green - positively identified slums, red - false identification).

Table 2. Ground truthing

\begin{tabular}{|l|l|l|l|l|}
\hline Point & $\begin{array}{l}\text { Satellite image } \\
\text { description }\end{array}$ & $\begin{array}{l}\text { Algorithm } \\
\text { result }\end{array}$ & On-site area description & $\begin{array}{l}\text { Ground } \\
\text { truthing result }\end{array}$ \\
\hline Point1 & $\begin{array}{l}\text { Large, homogeneous and } \\
\text { very dense settlement }\end{array}$ & Slum & $\begin{array}{l}\text { Informal and basic built-up, } \\
\text { very narrow streets }\end{array}$ & Slum \\
\hline Point 2 & $\begin{array}{l}\text { Small and very dense } \\
\text { settlement }\end{array}$ & Slum & $\begin{array}{l}\text { Basic built up, very narrow } \\
\text { streets }\end{array}$ & Slum \\
\hline Point 4 & $\begin{array}{l}\text { Large, homogeneous and } \\
\text { very dense settlement }\end{array}$ & Slum & $\begin{array}{l}\text { Basic built up, very narrow } \\
\text { streets }\end{array}$ & Slum \\
\hline Point 5 & $\begin{array}{l}\text { Stretch of very dense } \\
\text { settlement within a low- } \\
\text { density settlement } \\
\text { neighbourhood }\end{array}$ & Slum & $\begin{array}{l}\text { Informal and basic built-up, } \\
\text { very narrow streets }\end{array}$ & Slum \\
\hline
\end{tabular}




\begin{tabular}{|c|c|c|c|c|}
\hline Point 6 & $\begin{array}{l}\text { Large, homogeneous and } \\
\text { very dense settlement }\end{array}$ & Slum & Informal built-up & Slum \\
\hline Point 8 & $\begin{array}{l}\text { Medium-sized very dense } \\
\text { settlement }\end{array}$ & Slum & Basic built-up & Slum \\
\hline Point 9 & $\begin{array}{l}\text { Medium-sized very dense } \\
\text { settlement }\end{array}$ & Slum & $\begin{array}{l}\text { Informal and basic built-up, } \\
\text { very narrow streets }\end{array}$ & Slum \\
\hline Point 10 & $\begin{array}{l}\text { Large and dense } \\
\text { heterogeneous area in } \\
\text { the inner city }\end{array}$ & Slum & $\begin{array}{l}\text { Traditional built-up, not so } \\
\text { narrow streets }\end{array}$ & Not slum \\
\hline
\end{tabular}

\section{Discussion}

The results laid out in section 4 indicate that the sub-metre satellite imagery is a suitable data source for identification of slums in Hyderabad using advanced image analysis techniques. Satellite imagery is a snapshot in time that covers the complete area of the city. It is not dependent on historical slum notification and recognition processes meaning that a slum identification technique which is based on remote sensing data is well positioned to address the issues of changes in urban morphology caused by slum upgrading processes as well as rapid establishment of new slums.

Spatial distribution of new slums clearly identifies two major zones of slum growth: the north and the south of the city. Both regions are areas of industrial growth of the city, offering extensive lowskilled job opportunities in construction and production sectors. Establishing a slum in the vicinity of work (a large construction site, a quarry etc.) reduces the need to travel and creates financial and time benefits for workers.

The surprisingly high density of slums within and on the edges of upper class housing estates of Banjara and Jubilee Hills is the consequence of high demand for low-skilled and low-paid domestic services by the wealthy inhabitants of these parts of the city (Sengupta, 2009). The Old Town on the right bank of the Musi river, which is also characterised by high slum occurrence, is locally known to host a large fraction of poor and predominantly Muslim population inhabiting low-quality housing units. 
Setting the approximate slum population density at 55,000 inhabitants per square kilometre and lower and upper boundaries at 37,000 and 125,000 respectively (for literature review and the reasoning of the numbers see Kit et al., 2013), we perform a very rough first order quantification of slum population numbers in Hyderabad in 2010, which ranges between 700,000 and 2.3 million, with 1 million being the most probable value. Compared with 2003 numbers this means an impressive increase from approximately 600,000 slum inhabitants in 2010 (upper and lower probability boundaries 400,000 and 1.4 million).

\section{Summary and conclusions}

Combination of Canny edge detection, LSD segment detection and lacunarity provides a powerful and robust instrument for rapid automatic identification of informal settlements in the urban context of India. It offers a way to rapidly perform edge delineation, exclude non-linear features and ultimately calculate lacunarity as a proxy of slum probability in every cell within the urban area of Hyderabad.

This study proves the usefulness of advanced image processing methods in urban land use change detection research in a slum-plagued megacity of Hyderabad. It provides an insight into spatiotemporal slum development patterns in the city and questions the data collection procedures and the performance of counter-slum measures of the local administration between 2003 and 2010. It identified three trends in slum growth in Hyderabad, namely densification of existing settlements, slum growth on the fringes ('slum overflow') and spatial focus of slum growth in the north and in the south of the city.

It is worth mentioning that, as an aggregate function, lacunarity is obviously not capable to identify slums which are smaller than the resolution of the lacunarity matrix $\left(100 \times 100\right.$ pixels, $\left.3600 \mathrm{~m}^{2}\right)$. Therefore, the methodology described in this paper should be only used to identify slums occupying more than $3600 \mathrm{~m}^{2}$.

The methodology suggested by this paper can be used to assess the performance of urban management practices in different parts of Hyderabad and probably - in other large urban agglomeration across the Indian subcontinent. The Government of India and the administration of Hyderabad frequently report about the progress towards reaching the slum-free cities goal. The use 
of rapid remote sensing-based slum assessment techniques is a meaningful way to perform the firstorder slum assessment process and to identify areas that require further attention.

One of the key advantages of the algorithm is its complete reliance on free open source software tools and very modest hardware requirements. Reasonably low costs of the method result in an increased ability to analyse more data, making this approach suitable in financially tight situation of many cities of the global South. In situations where funding constraints make impossible the acquisition of multi-temporal very high resolution imagery, an alternative ASTER-based approach suggested by Stoler et al., 2012 may be used as well.

If combined with extreme precipitation-induced flood risk map of the city (Kit et al., 2011), this study can identify newly established slums which settle on the most endangered sites. Since many of them consist of temporary housing units and lack the solidity of the infrastructure of long established slums, such settlements can be classified as particularly vulnerable ones. The authors believe that the results of slum detection using the algorithm proposed in this paper can be used to prepare a subset of the areas of interest to be analysed using other, less automated methods such as the generic slum ontology proposed by Kohli et al., 2012.

The authors are highly interested to apply the methodology on other cities in the developing world and invite the international research community to cooperation. The next steps of this research will consist of acquisition and analysis of very high resolution satellite imagery from other cities of India, and in further improvement of algorithm accuracy.

\section{ACKNOWLEDGEMENTS}

The authors acknowledge financial support from the Federal Ministry of Education and Research of Germany (BMBF) under the project "Future Megacities". 


\section{References}

1. Amorim, L., Barros Filho, M. N., Cruz, D., 2009. Analysing Recife's urban fragments. In: Koch, D., Lars, M., Steen, J. (Eds.), Proceedings of the 7th International Space Syntax Symposium. KTH, Stockholm, Sweden, 003:1-14.

2. Awrangjeb, M., Ravanbakhsh, M., Fraser, C., 2010. Automatic detection of residential buildings using LIDAR data and multispectral imagery. ISPRS Journal of Photogrammetry and Remote Sensing 65 (5), 457-467.

3. Bailly, J.S., Levavasseur, F., 2012. Mapping of linear elements over cultivated landscape using VHSR data. PleiadesDay, Toulouse.

4. Bong, D., Chun Lai, K., Joseph, A., 2009. Automatic Road Network Recognition and Extraction for Urban Planning. International Journal of Applied Science, Engineering and Technology 5 (1), 209-215.

5. Bostel, F., 2012. Validierung und Kalibrierung von remote-sensing basierten Temperaturund Siedlungsstrukturdaten für die urbane Agglomeration Hyderabad/Indien. Bachelor Thesis, Albert-Ludwig University Freiburg, 60 pp.

6. Canny, J., 1986. A computational approach to edge detection. IEEE Transactions on Pattern Analysis and Machine Intelligence, 8(6), 679-698.

7. von Giou, R.G., Jakubowicz, J., J.M. Morel, J.M., Randall, G., 2012. LSD: a line segment detector. Image Processing On Line, 24 March, 2012.

8. Government of India, 2010. Report of the Committee on Slum Statistics/Census. Ministry of Housing and Urban Poverty Alleviation, New Delhi, India.

9. Grigillo, D., Fras, M., Petrovič, D., 2012. Automated building extraction from IKONOS images in suburban areas. International Journal of Remote Sensing. 33 (16), 5149-5170.

10. Gunn, S., 1999. On the discrete representation of the Laplacian of Gaussian. Pattern Recognition 32 (8), 1463-1472.

11. Hofmann, P., Strobl, J., Blaschke, T., \& Kux, H., 2008. Detecting informal settlements from Quickbird data in Rio De Janeiro using an object based approach. In: Blaschke, T., Lang, S., Hay, G.J. (Eds.), Object-based Image Analysis, Springer, pp. 531-553.

12. Jain, S., 2007. Use of IKONOS satellite data to identify informal settlements in Dehradun, India. International Journal of Remote Sensing 28(15), 3227 - 3233.

13. Khelifa, D., Mimoun, M., 2012. Object-based image analysis and data mining for building ontology of informal urban settlements. In: Bruzzone, L. (Ed.), Proc. Image and Signal Processing for Remote Sensing XVIII 8537, Edinburgh, UK, 24-26 September, doi:10.1117/12.974444. 
14. Kit O., Lüdeke M., Reckien D., 2011. Assessment of climate change-induced vulnerability to floods in Hyderabad/India using remote sensing data. In: Otto-Zimmermann, K. (Ed.), Resilient Cities - Cities and Adaptation to Climate Change, Local Sustainability, 1(2), 35-44.

15. Kit, O., Lüdeke, M., Reckien, D., 2012. Texture-based identification of urban slums in Hyderabad, India using remote sensing data. Applied Geography 32 (2), 660-667.

16. Kit, O., Lüdeke, M., Reckien, D., 2013. Defining the bull's eye: satellite imagery-assisted slum population assessment in Hyderabad, India. Urban Geography 34(1), in press.

17. Kohli, D., Sliuzas, R., Kerle, N., Stein, A., 2012. An ontology of slums for image-based classification. Computers, Environment and Urban Systems 36 (2) 154-163.

18. Marr, D., Hildreth, E., 1980. Theory of edge detection, Proc. Roy Soc. Lond 207, 187-217.

19. $\mathrm{MCH}$. (2005). Draft city development plan. Hyderabad: Municipal Corporation of Hyderabad.

20. Owen, K., Wong, D., 2013. An approach to differentiate informal settlements using spectral, texture, geomorphology and road accessibility metrics. Applied Geography 38, 107-118.

21. Peeters, A., Etzion, Y., 2012. Automated recognition of urban objects for morphological urban analysis. Computers, Environment and Urban Systems 36 (6), 573-582.

22. Poulain, V., Inglada, J., Spigai, M., Tourneret, J.-Y., Marthon, P., 2011. High-resolution optical and SAR image fusion for building database updating. IEEE Transactions on Geoscience and Remote Sensing, 49 (8), 2900-2910.

23. Rhinane, H, Hilali, A, Berrada, A., Hakdaoui, M., 2011. Detecting Slums from SPOT Data in Casablanca Morocco Using an Object Based Approach. Journal of Geographic Information System 3(3), 217-224.

24. Risbud, N., 2010. Typology of Slums and Land Tenure in Indian Cities. Presentation at the National Workshop on Land Tenure Issues in Slum Free Planning, Ahmadabad, India, August 30, 2010.

25. Satterthwaite, D., 2004. The under-estimation of urban poverty in low- and middle-income nations. Poverty Reduction in Urban Areas Working Paper 14, IIED, London, United Kingdom.

26. Sengupta, S., 2009. Of bungalows and bastis of Banjara Hills. The Times of India. 13 November 2009.

27. Shekhar, S., 2012. Detecting slums from QuickBird data in Pune using an object-oriented approach. International Archives of the Photogrammetry, Remote Sensing and Spatial Information Sciences, 39 (8), 519-524.

28. Sliuzas, R., Mboup, G., \& de Sherbinin, A. (2008) Report of the expert group meeting on slum identification and mapping. Report by CIESIN, UN-Habitat, ITC, p. 36. 
29. Stoler, J., Daniels, D., Weeks, J., Stow, D., Coulter, L., 2012. Assessing the Utility of Satellite Imagery with Differing Spatial Resolutions for Deriving Proxy Measures of Slum Presence in Accra, Ghana. GIScience \& Remote Sensing 49 (1), 31-52.

30. Taubenböck, H., Kraff, N.J., 2013. The physical face of slums: a structural comparison of slums in Mumbai, India, based on remotely sensed data. J Hous and the Built Environ, online first.

31. The Times of India. World Bank team visits Hyderabad slums. 12 June 2012.

32. UN, 2011. UN Data Glossary, http://data.un.org/Glossary.aspx . (Accessed 2 February, 2011)

33. UN, 2012. The future we want: Cities. Factsheet produced by United Nations Department of Public Information at Rio+20 UN Conference on Sustainable Development.

34. Ünsalan, C., 2009. Statistical, structural, hybrid, and graph theoretical features to measure land development. IEEE Geoscience and Remote Sensing Letters 6 (1), 72-76.

35. Veljanovski, T., Kanjir, U., Pehani, P., Oštir, K., Kovačič, P., 2012. Object-Based Image Analysis of VHR Satellite Imagery for Population Estimation in Informal Settlement Kibera-Nairobi, Kenya. In: Escalante-Ramirez, B. (Ed.), Remote Sensing - Applications. InTech. pp. 407-436.

36. Weeks, J. R., Hill, A. G., Stow, D. A., Getis, A., and D. Fugate, 2007. Can We Spot a Neighborhood From the Ground? Defining Neighborhood Structure in Accra, Ghana. Geojournal 69, 9-22.

37. Zhan, Q., Shi, W., Xiao, Y., 2005. Quantitative analysis of shadow effects in high-resolution images of urban areas. ISPRS Archives 36-8. 